\title{
Hunting Nematodes in the Pine Forests of Northern Greece: A Preliminary Overview after One Year of Surveys ${ }^{\dagger}$
}

\author{
Maria Karmezi 1,2, , Alkmini Bataka ${ }^{1}$, Dimitrios Papachristos ${ }^{3}$ and Dimitrios N. Avtzis ${ }^{1}$ \\ 1 Forest Research Institute, Hellenic Agricultural Organization Demeter, Vassilika 57006, Thessaloniki, \\ Greece; alkminimp@fri.gr (A.B), dimitrios.avtzis@fri.gr (D.A.) \\ 2 Zoology Department, School of Biology, Faculty of Sciences, Aristotle University of Thessaloniki, Thessalo- \\ niki 54124, Greece \\ 3 Department of Entomology and Agricultural Zoology, Benaki Phytopathological Institute, Kifissia 14561, \\ Athens, Greece; d.papachristos@bpi.gr \\ * Correspondence: mkarmezi@bio.auth.gr \\ + Presented at the 1st International Electronic Conference on Entomology (IECE 2021), 1-15 July 2021; \\ Available online: https://iece.sciforum.net/.
}

Citation: Karmezi, M.; Bataka, A.; Papachristos, D., Avtzis, D. Hunting nematodes in the pine forests of Northern Greece: a preliminary overview after one year of surveys, in Proceedings of the 1st International Electronic Conference on Entomology, 1-15 July 2021, MDPI: Basel, Switzerland, doi:10.3390/IECE10526

Published: 1 July 2021

Publisher's Note: MDPI stays neutral with regard to jurisdictional claims in published maps and institutional affiliations.

Copyright: (c) 2021 by the authors. Submitted for possible open access publication under the terms and conditions of the Creative Commons Attribution (CC BY) license (http://creativecommons.org/licenses /by/4.0/).

\begin{abstract}
Pine wood nematode (PWN) Bursaphelenchus xylophilus is one of the most important forest tree pathogens worldwide, causing Pine Wilt Disease. Facilitated by international trade, PWN has expanded beyond its natural range becoming one of the most notorious quarantine pests. To prevent its further expansion, national survey programs are being widely established. Accordingly, such a network has also been established in Greece collecting and examining wood samples nationwide. So far, B. xylophilus was absent from all samples examined, although four other Bursaphelenchus species were identified, along with other nematode taxa. Evidently, besides preventing the introduction of B. xylophilus, national survey programs can further increase our knowledge regarding tree-inhabiting nematodes.
\end{abstract}

Keywords: Bursaphelenchus spp.; national survey program; nematodes; conifers; Greece

\section{Introduction}

The Pine Wood Nematode (PWN) Bursaphelenchus xylophilus (Steiner \& Buhrer 1934) Nickle 1970 is one of the most important pathogens of high economic importance worldwide, causing the Pine Wilt Disease. The PWN has managed to expand its range following the routes and pathways employed by the international trade. Coupled with the detrimental impact it has on pine forests [1,2], it has been listed as a quarantine pest in more than 40 countries in the EU [3] and considered one of the most important pests and pathogens in the world [2].

PWN can be easily transferred via wood trade either as a commodity (e.g., live plants, wood logs, sawn wood), or as Wood Packaging Material (WPM) [4]. It was introduced to Eastern Asia and Western Europe by human activities and international trade [5]. It was first recorded in Japan at the beginning of the twentieth century [6,7] where it was probably transferred with timber exported from North America and has caused significant damages in pine forests since then. Bursaphelenchus xylophilus was also introduced to China, Taiwan, and Korea where it was detected in mid to late 1980s [8]. In Europe, it was reported for the first time in Portugal in 1999 [9] and in 2008 the first report of B. xylophilus was confirmed in Spain [10].

Since its introduction into new regions, it has become evident that the impact of $B$. xylophilus is more pronounced in the areas where it has been introduced compared to its natural range such as North America, Canada and the United States [11], and Mexico [12]. In fact, it has been noticed that while North American pine species are resistant or at least 
tolerant to B. xylophilus, exotic species such as P. nigra, P. sylvestris, and P. thunbergii, planted in North America, especially in the warmer southern areas of the United States, are most susceptible $[8,12,13]$.

Since B. xylophilus expansion and its establishment outside its natural range there have been reports of many damaging effects on forest ecosystems and simultaneous major economic impacts $[14,15]$ while further future and even higher economic impacts are assumed to be expected [16]. After its first detection in Portugal and Spain, it has become evident that PWN poses a major threat for the pine forests along the Mediterranean basin. This becomes apparent considering the large extent of pine forests [17], the favorable climatic conditions [18] in combination to climate change scenarios [19] and the occurrence of its vector Monochamus galloprovincialis (Olivier 1795) in many countries [20,21]. To avoid its further expansion, national survey programs screen several samples from trees showing symptoms similar to the ones caused by PWN all over Europe. In this direction, some results from Greece are presented here, emphasizing on the fact that beside preventing the introduction of B. xylophilus, surveys can substantially contribute to our knowledge on the nematode species inhabiting pine trees in Greece.

\section{Materials and Methods}

In the framework of the National Survey Program regarding the PWN, wood samples were collected from northern and central Greece and the northern Aegean islands, and then examined at the Forest Research Institute in Thessaloniki. Forty-five (45) wood samples in total were collected from declining or symptomatic conifer trees. Samples were processed immediately after arriving at the laboratory. Nematodes were extracted using a modified Baermann funnel technique. For each sample, approximately $10 \mathrm{gr}$ of wood chips were soaked in water for at least 24 hours at room temperature. A binocular stereoscope was then used for the detection of nematode presence while individual nematodes were picked with a micropipette and mounted on a glass slide for further identification under a microscope. Nematode identification was made based on their morphological characteristics [11,22].

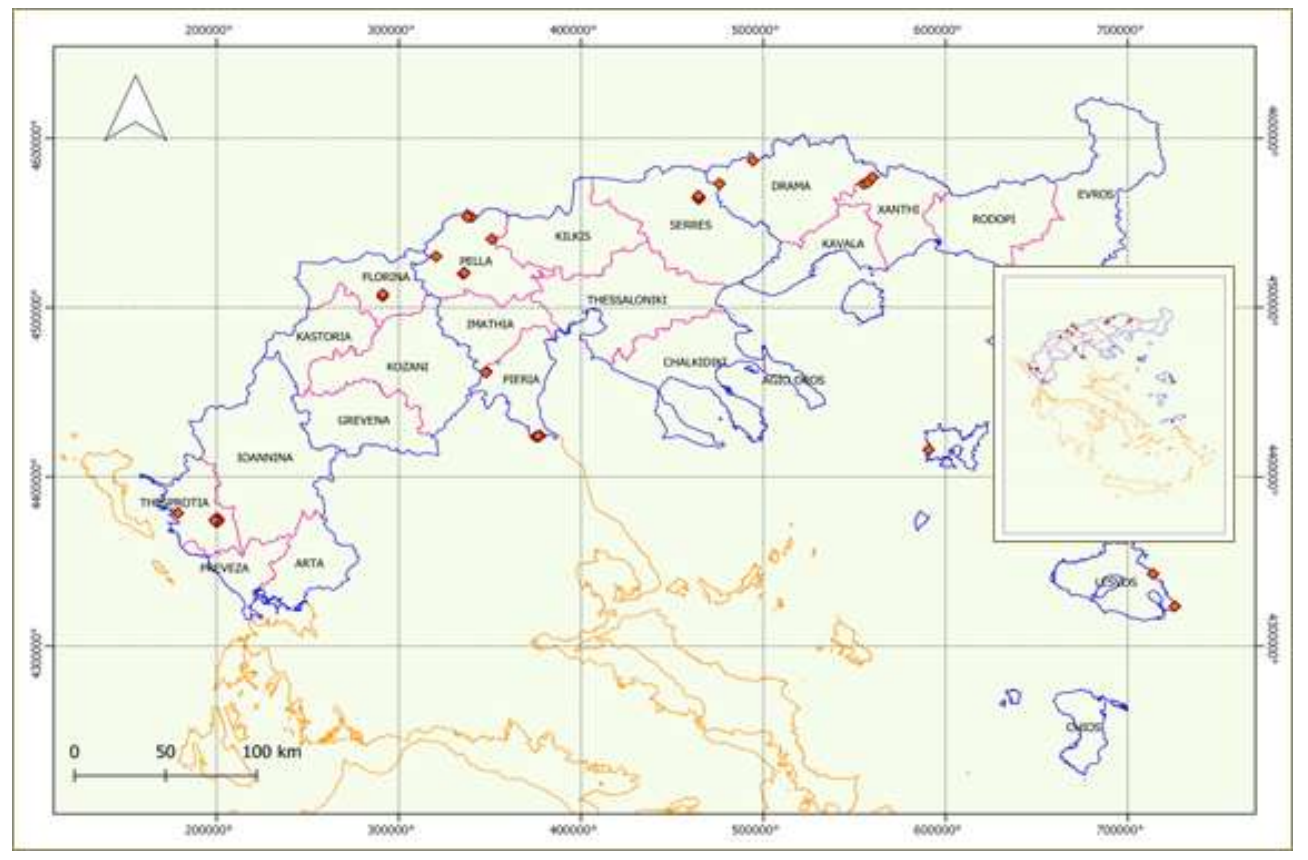

Figure 1. Sampling sites covering north and central Greece and part of the northern Aegean islands. 


\section{Results}

Out of the 45 samples examined (Figure 1), nematodes were detected in 13 samples, i.e., $29 \%$ of the samples. Even though B. xylophilus was not detected in any of the 13 samples, other Bursaphelenchus spp. were detected in 8 of them (62\%). From these 8 samples, all samples contained only one Bursaphelenchus species ( $87 \%$ of the samples), except for one sample containing two Bursaphelenchus species. A large number of samples $(69 \%$ - 9 samples) also contained other nematode taxa besides Bursaphelenchus species. In particular, four Bursaphelenchus species were identified: B. hellenicus Skarmoutsos, Braasch, Michalopoulou 1998, B. mucronatus Mamiya and Enda 1979, B. leoni Baujard 1980 and Bursaphelenchus sp.1. There were also some Bursaphelenchus sp. individuals that could not be assigned to one particular species (Table 1). The fact that, either individuals were at a very immature stage, or in a bad condition after the extraction, made any further identification to species level very difficult. All Bursaphelenchus species were encountered with the same frequency.

Regarding the other nematode species that were detected (Table 1), they belong to Aphelenchoides sp., Tylencholemaillus sp. (fungivores), Anguinidae (fungivores/ plant feeders), Panagrolaimus sp. (bacterivores), Clarkus sp. (predators) and Parasitorhabditis sp. (entomophilic).

Samples with Bursaphelenchus species and other nematode taxa are located in three administrative regions: Drama, Pella and Thesprotia, while other nematode taxa were also found in Pieria region in addition to the other three regions (Table 1).

Table 1. Regions, conifer species and detected nematodes.

\begin{tabular}{cccc}
\hline Regions & Conifer species & Bursaphelenchus spp. & Other nematodes \\
\hline Aridaia & Abies borisii-regis & B. mucronatus & \\
& Pinus silvestris & Bursaphelenchus sp.1 & \\
Neurokopi & Pinus silvestris & B. hellenicus & Anguinidae \\
& Pinus silvestris & B. leoni & \\
& Pinus sp. & B. mucronatus & Parasitorhabditis sp. \\
Pella & Pinus sp. & Bursaphelenchus sp.1 & \\
& Pinus sp. & Bursaphelenchus sp. ${ }^{+}$ & Aphelenchoides sp. \\
Pieria & Pinus nigra & & Panagrolaimus sp. \\
Thesprotia & Pinus sp. & B. hellenicus & Tylencholaimellus sp. \\
& Pinus sp. & Bursaphelenchus sp. & Clarkus sp. \\
& Pinus sp. & & Other nematodes \\
\hline
\end{tabular}

${ }^{\dagger}$ Bursaphelenchus individuals that could not be identified.

\section{Discussion}

Bursaphelenchus xylophilus was absent from all samples with nematode presence while other Bursaphelenchus spp. were detected in more than half of the samples with nematode detection indicating a strong presence of this genus. The identified Bursaphelenchus species were: B. hellenicus, B. mucronatus, B. leoni and Bursaphelenchus sp.1. Detection of these species in the current study is validated by previous studies in Greece. In particular, B. hellenicus, B. leoni and B. mucronatus, have already been documented for Greece $[23,24]$. Regarding the unidentified Bursaphelenchus sp.1, it resembles B. vallesianus, a member of the "sexdentati" group sensu Braasch [25] and Braasch et al. [22], a species also detected in Greece in specimens isolated by E. Skarmoutsos during 1997 and 1998 and analyzed by Lange et al. [26]. In further support of these findings, most of these species have also been documented in neighboring countries. For example, in Cyprus, apart from B. leoni $[27,28]$, $B$. borealis, $B$. idius B. sexdentati and B. teratospicularis [28] have also been recovered from trees in a bad condition, wilted or damaged. In Italy besides B. hellenicus, B. mucronatus, $B$. leoni, B. sexdentati, and B. teratospicularis $[29,30]$ other members of the Bursaphelenchus 
genus like B. abietinus, B. andrassyi, B. eremus, B. fraudulentus, B. fungivorous, B. minutus and B. tusciae [30-34] have been identified. In Turkey, B. anamurius, B. hellenicus, B. mucronatus, B. pinophilus, B. sexdentati and B. vallesianus have been identified by Akbulut et al. [35-39]: $B$. anamurius, B. hellenicus, B. mucronatus, B. pinophilus, B. sexdentati and B. vallesianus.

Generally, B. mucronatus was long considered the most abundant Bursaphelenchus species in Central Europe but relatively rare in the Mediterranean region according to Braasch [25]. Nevertheless, recent studies have shown that B. mucronatus is quite frequent around the Mediterranean region and the Balkan Peninsula [40], an issue that was also retrieved in the current study. In contrast, $B$. leoni is referred as a typical Mediterranean species, based on its widespread and frequent occurrence there, although it has also occasionally been found in Central Europe. Bursaphelenchus hellenicus besides Greece [41] has also been documented in two other Mediterranean countries such as Italy [30] and Turkey [39]. As for B. xylophilus presence in Europe, so far it has been detected only in Portugal [2] and Spain [10,42].

Apart from Bursaphelenchus spp., other nematode taxa were also recovered in many samples, something that has also been frequently reported $[28,29,37,43,44]$. These taxa range from saproxylic and entomophilic, to phytophagous, predatory and fungal-associated nematodes [45]. For example, Caroppo et al. [29] state that Rhabditida and other Aphelenchida occurred in most pine wood samples, while Tylenchida presence was occasional and restricted to a limited number of specimens. Dod et al. [46] found that saprophytic nematodes (Rhabditidae, Diplogasteridae and Cephalobidae) dominated along the entire coastal region of Croatia while Bursaphelenchus spp. presence was quite low.

Summarizing, it is easily deduced that in the framework of the national survey programs focusing on B. xylophilus, significant knowledge can be gained and accumulated regarding other Bursaphelenchus and nematode species as well. It should be made clear that B. xylophilus is not the only pathogenic Bursaphelenchus species. In Greece for example, among the Bursaphelenchus species identified so far, B. mucronatus, B. vallesianus and $B$. sexdentati have been characterized to be highly pathogenic $[43,47,48]$, although such findings have not been confirmed under natural forest stand conditions [49]. However, such pathogenicity results are indicative of the species pathogenic potential and detection of such Bursaphelenchus species could add to the knowledge of the condition pine forests are at present in Greece.

Author Contributions: Conceptualization, D.P. and D.N.A.; methodology, D.P. and D.N.A.; validation, M.K. and D.N.A.; formal analysis, M.K.; investigation, M.K.; resources, A.B and D.N.A.; data curation, M.K.; writing - original draft preparation, M.K.; writing - review and editing, M.K., A.B., D.N.A and D.P.; visualization, M.K.; supervision, D.N.A.; project administration, A.B. and D.N.A; funding acquisition, D.P. and D.N.A. All authors have read and agreed to the published version of the manuscript.

Funding: The study was partially funded by the Greek Ministry of Rural Development and Food under the national plant pest surveillance program.

Institutional Review Board Statement: Not applicable.

Informed Consent Statement: Not applicable.

Data Availability Statement: The data presented in this study are available on request from the corresponding author.

Acknowledgments: Phytosanitary Inspectors of Forest Directorates and Forestry offices for their assistance in the collection and submission of samples.

Conflicts of Interest: The authors declare no conflict of interest. 


\section{References}

1. Vicente, C.; Espada, M., Vieira, P., Mota, M. Pine wilt disease: A threat to European forestry. Eur J. Plant. Pathol 2012, 133, 8999, doi:10.1007/s10658-011-9924-x.

2. Inácio, M.; Nobrega, F., Vieira, P., Bonifacio, L., Naves, P., Sousa, E., Mota, M. First detection of Bursaphelenchus xylophilus associated with Pinus nigra in Portugal and in Europe. For. Pathol 2015, 45, 235-238, doi:10.1111/efp.12162.

3. Back, M. Pine Wilt Disease a global threat to forestry. Plant Pandemic Study 4 2020, British Society for Plant pathology. Available online: https://www.bspp.org.uk/ (accessed in 15/06/2021).

4. Sousa, E.; Naves, P., Bonifácio, L., Inácio, L., Henriques, J., Evans, H. Survival of Bursaphelenchus xylophilus and Monochamus galloprovincialis in pine branches and wood packaging material. Bull. OEPP/EPPO Bull. 2011, 41, 203-207, doi:10.1111/j.13652338.2011.02463.x.

5. Tóth, Á. Bursaphelenchus xylophilus, the pinewood nematode: Its significance and a historical review. Acta Biol Szeged 2011, 55, 213-217.

6. Liebhold, A.M.; MacDonald, W.L., Bergdahl, D., Mastro, V.C. Invasion by exotic forest pests: A threat to forest ecosystems. For. Sci 1995, 41(suppl_1), a0001-z0001, doi:10.1093/forestscience/41.s1.a0001.

7. Zhang, K.; Liu, H., Sun, J., Liu, J., Fei, K., Zhang, C., Xu, M., Sun, J., Ma, X., Lai, R. Molecular phylogeny of geographical isolates of Bursaphelenchus xylophilus: Implications on the origin and spread of this species in China and worldwide. J. Nematol 2008, 40, 127-137.

8. ISPM 27. Annex 10. Bursaphelenchus xylophilus. IPPC, FAO: Rome, 2016.

9. Mota, M.M.; Braasch, H., Bravo, M.A., Penas, A.C., Burgermeister, W., Metge, K., Sousa, E. First report of Bursaphelenchus $x y$ lophilus in Portugal and in Europe. Nematology 1999, 1, 727-734, doi:10.1163/156854199508757.

10. Robertson, L.; Arcos, S.C., Escuer, M., Merino, R.S., Esparrago, G., Abelleira, A., Navas, A. Incidence of the pinewood nematode Bursaphelenchus xylophlius Steiner \& Buhrer, 1934 (Nickle, 1970) in Spain. Nematology 2011, 13, 755-757, doi:10.1163/138855411X578888.

11. Ryss, A.; Vieira, P., Mota, M., Kulinich, O. A synopsis of the genus Bursaphelenchus Fuchs, 1937 (Aphelenchida: Parasitaphelenchidae) with keys to species. Nematology 2005, 7, 393-458, doi:10.1163/156854105774355581.

12. Dwinell, L. First report of pinewood nematode (Bursaphelenchus xylophilus) in Mexico. Plant. Dis 1993, 77.

13. Bergdahl, D. Impact of pinewood nematode in North America: Present and future. J. Nematol 1988, 20, $260-265$.

14. Evans, H.; McNamara, D., Braasch, H., Chadoeuf, J., Magnusson, C. Pest risk analysis (PRA) for the territories of the European Union (as PRA area) on Bursaphelenchus xylophilus and its vectors in the genus Monochamus. Bull. OEPP/EPPO Bull. 1996, 26, 199-249.

15. European and Mediterranean Plant Protection Organization. Available online: https://gd.eppo.int (accessed on 18/08/2020).

16. Soliman, T.; Mourits, M.C., Van Der Werf, W., Hengeveld, G.M., Robinet, C., Lansink, A.G.O. Framework for modelling economic impacts of invasive species, applied to pine wood nematode in Europe. PLoS ONE 2012, 7, e45505, doi:10.1371/journal.pone.0045505.

17. Leone, V.; Lovreglio, R. Conservation of Mediterranean pine woodlands: Scenarios and legislative tools. Plant. Ecol 2004, 171, 221-235, doi:10.1023/B:VEGE.0000029377.59216.e5.

18. REPHRAME: Development of improved methods for detection, control and eradication of pine wood nematode in support of EU Plant. Health policy. 2015 Final project report. Available online: http://www.rephrame.eu (accessed on 01/05/2021).

19. Hirata, A.; Nakamura, K., Nakao, K., Kominami, Y., Tanaka, N., Ohashi, H., Takano, K.T., Takeuchi, W., Matsui, T. Potential distribution of pine wilt disease under future climate change scenarios. PLoS ONE 2017, 12, e0182837, doi:10.1371/journal.pone.0182837.

20. Akbulut, S.; Stamps, W. Insect vectors of the pinewood nematode: A review of the biology and ecology of Monochamus species. For. Pathol 2012, 42, 89-99, doi:10.1111/j.1439-0329.2011.00733.x.

21. Haran, J.; Rousselet, J., Tellez, D., Roques, A., Roux, G. Phylogeography of Monochamus galloprovincialis, the European vector of the pinewood nematode. J. Pest. Sci 2018, 91, 247-257, doi:10.1007/s10340-017-0878-4.

22. Braasch, H.; Burgermeister, W., Gu, J. Revised intra-generic grouping of Bursaphelenchus Fuchs, 1937 (Nematoda: Aphelenchoididae). J. Nematode Morphol Syst 2009, 12, 65-88.

23. Skarmoutsos, G.; Skarmoutsou, H. First record of Bursaphelenchus nematodes from pine forests in Greece. Plant. Dis 1999, 83, 879-879, doi:10.1094/PDIS.1999.83.9.879D.

24. Michalopoulos-Skarmoutsos, H.; Skarmoutsos, G., Kalapanida, M., Karageorgos, A. Surveying and recording of nematodes of the genus Bursaphelenchus in conifer forests in Greece and pathogenicity of the most important species, In The pinewood nematode, Bursaphelenchus xylophilus. Proceedings of an International Workshop, University of Évora, Portugal, 20-22 August 2001, Eds. Mota, M., Vieira, P.; Brill Academic Publishers: Leiden, Netherlands, 2004, 113-126.

25. Braasch, H. Bursaphelenchus species in conifers in Europe: Distribution and morphological relationships. Bull. OEPP/EPPO Bull. 2001, 31, 127-142, doi:10.1111/j.1365-2338.2001.tb00982.x.

26. Lange, C.; Burgermeister, W., Metge, K., Braasch, H. Molecular Characterization of Isolates of the Bursaphelenchus sexdentati Group Using Ribosomal DNA Sequences and ITS-RFLP. In Pine Wilt Disease: A Worldwide Threat to Forest Ecosystems, 1st ed.; Eds. Mota, M., Vieira, P.; Springer: Dordrecht, Netherlands: 2008; pp 165-173, doi:10.1007/978-1-4020-8455-3_14. 
27. Philis, J.; Braasch, H. Occurrence of Bursaphelenchus leoni (Nematoda, Aphelenchoididae) in Cyprus and its extraction from pine wood. Nematol Mediterr 1996, 24, 119-123.

28. Braasch, H.; Philis, J. New records of Bursaphelenchus spp. in Cyprus. Nematol Mediterr 2002, 30, 55-57.

29. Caroppo, S.; Ambrogioni, L., Cavalli, M., Coniglio, D. Occurrence of the pine wood nematodes, Bursaphelenchus spp., and their possible vectors in Italy. Nematol Mediterr 1998, 26, 87-92.

30. Torrini, G.; Paoli, F., Mazza, G., Simoncini, S., Strangi, A., Guidotti, A., Mori, E., Roversi, P.F., Marianelli, L. First detection of Bursaphelenchus abietinus and B. andrassyi in Italy. For. Pathol 2020, 50, e12627, doi:10.1111/efp.12627.

31. Ambrogioni, L.; Palmisano, A.M., Description of Bursaphelenchus tusciae sp. n. from Pinus pinea in Italy. Nematol Mediterr 1998, $26,243-254$.

32. Carletti, B.; Irdani, T., Cosi, E., Brandstetter, M., Pennacchio, F., Roversi, P.F., Ambrogioni, L. First record of Bursaphelenchus fraudulentus Rühm (Goodey) (Nematoda Aphelenchoididae) in Italy. Redia 2006, 88, 27-35.

33. Carletti, B.; Ambrogioni, L., Irdani, T., Brandstetter, M., Puleri, F., Surico, F., Pennacchio, F., Roversi, P. Morphometrics and molecular identification of some Italian populations of Bursaphelenchus eremus Rühm (Goodey) associated with Quercus spp. Redia 2007, 90, 3-21.

34. Torrini, G.; Strangi, A., Simoncini, S., Luppino, M., Roversi, P.F., Marianelli, L. First report of Bursaphelenchus fungivorus (Nematoda: Aphelenchida) in Italy and an overview of nematodes associated with Crocus sativus L. J. Nematol 2020, 52, e2020-e2023, doi:10.21307/jofnem-2020-023.

35. Akbulut, S.; Vieira, P., Ryss, A., Yuksel, B., Keten, A., Mota, M., Valadas, V. Preliminary survey of the pinewood nematode in Turkey. Bull. OEPP/EPPO Bull. 2006, 36, 538-542, doi:10.1111/j.1365-2338.2006.01056.x.

36. Akbulut, S.; YÜKSEL, B., Serin, M., Baysal, I., Erdem, M. Pathogenicity of Bursaphelenchus mucronatus in pine seedlings under greenhouse conditions. Turk. J. Agric. For. 2007, 31, 169-173.

37. Akbulut, S.; Vieira, P., Ryss, A., Valadas, V., Keten, A., Mota, M. Bursaphelenchus Fuchs, 1937 (Nematoda: Parasitaphelenchidae) species associated with Pinus species in northern Turkey. Helminthologia 2008, 45, 89-95, doi:10.2478/s11687-008-0017-0.

38. Akbulut, S.; Elekçioğlu, I.H., Keten, A. First record of Bursaphelenchus vallesianus Braasch, Schönfeld, Polomski, and Burgermeister in Turkey. Turk. J. Agric. For. 2008, 32, 273-279.

39. Akbulut, S.; Braasch, H., Cebeci, H. First report of Bursaphelenchus hellenicus Skarmoutsos, Braasch, Michalopoulou (Nematoda: Aphelenchoididae) from Turkey. For. Pathol 2013, 43, 402-406, doi:10.1111/efp.12045.

40. d'Errico, G.; Carletti, B., Schröder, T., Mota, M., Vieira, P., Roversi, P.F. An update on the occurrence of nematodes belonging to the genus Bursaphelenchus in the Mediterranean area. Forestry (Oxf) 2015, 88, 509-520, doi:10.1093/forestry/cpv028.

41. Skarmoutsos, G.; Braasch, H., Michalopoulou, H. Bursaphelenchus hellenicus sp. n. (Nematoda, Aphelenchoididae) from Greek pine wood. Nematologica 1998, 44, 623-629, doi:10.1163/005725998X00032.

42. Abelleira, A.; Picoaga, A., Mansilla, J., Aguin, O. Detection of Bursaphelenchus xylophilus, causal agent of pine wilt disease on Pinus pinaster in Northwestern Spain. Plant. Dis 2011, 95, 776-776, doi:10.1094/PDIS-12-10-0902.

43. Polomski, J.; Rigling, D. Effect of watering regime on disease development in Pinus sylvestris seedlings inoculated with Bursaphelenchus vallesianus and B. mucronatus. Plant. Dis 2010, 94, 1055-1061, doi:10.1094/PDIS-94-8-1055.

44. Prospero, S.; Polomski, J., Rigling, D., Occurrence and ITS diversity of wood-associated Bursaphelenchus nematodes in Scots pine forests in Switzerland. Plant. Pathol. 2015, 64, 1190-1197, doi:10.1111/ppa.12356.

45. Andreieva, O.; Korma, O., Zhytova, O., Martynchuk, I., Vyshnevskyi, A. Beetles and nematodes associated with wither Scots pines. Lesn Cas 2020, 66, 49-59, doi:10.2478/forj-2020-0001.

46. Đođ, N.; Cota, E., Pernek, M. Wood nematode species spectrum in the Mediterranean pine forests of Croatia. Period. Biol 2015, 117, 505-512, doi:0.18054/pb.2015.117.4.3442.

47. Skarmoutsos, G.; Michalopoulos-Skarmoutsos, H. Pathogenicity of Bursaphelenchus sexdentati, Bursaphelenchus leoni and Bursaphelenchus hellenicus on European pine seedlings. For. Pathol 2000, 30, 149-156, doi:10.1046/j.1439-0329.2000.00198.x.

48. Akbulut, S.; Yüksel, B., Serin, M., Erdem, M. Comparison of pathogenic potential of Bursaphelenchus species on conifer seedlings between greenhouse and outdoor conditions. Phytoparasitica 2015, 43, 209-214, doi:10.1007/s12600-014-0433-2.

49. Öztürk, N.; Akbulut, S., Baysal, İ. Determination of pathogenicity of Bursaphelenchus species on different pine species under natural conditions in Düzce. Phytoparasitica 2019, 47, 89-97, doi:10.1007/s12600-018-00708-9. 